\section{STENOSIS OF THE TRACHEA AFTER TRACHEOTOMY.}

By PRIESTLEY LEECH, M.D., B.S. LoND., F.R.C.S. ENG., SURGEON TO THE HALIFAX INFIRMARY.

THE following case is interesting for several reasons : (1) It is an example of what is thought to be a rare occurrence -namely, stenosis following the use of a metal tracheotomy tube; (2) the recovery in so young a child after tracheotomy and thyrotomy shows, I think, that the wellknown fatality of tracheotomy in young children is due not so much to the operation itself as to the disease-diphtheriafor which it is generally performed; (3) it also shows the necessity, which has so often been insisted upon, of replacing the metal tube as soon as possible by a rubber tube; (4) it is also another instance of the necessity for exploration of the larynx and tracheotomy wound when the patient is nnable to breathe through the natural passage after tracheotomy for a foreign body ; and (5) the sudden death of the child some time later (probably from a recurrence of the stenosis) indicates the advisability of keeping under observation the cases of tracheotomy in which there has been stenosis of the trachea. At the time this case occurred the paper by Messrs. Pitts and Brook on "Stenosis of the Trachea and Larynx" had not been published or I might have tried intubation to overcome the stenosis. If, however, another case were to present itself, I think I should be more inclined to try the T-shaped tube described by Mr. C. J. Bond in THE LANCET of March 7th, 1891, until the tendency to contraction had been overcome ; for the contraction in my case was confined to the end of the trachea immediateily above the tracheotomy wound. I see no reason why this T-shaped tube should not be made of strong rubber, thus minimising to some extent the irritation caused by a metal tube.

The patient, a male child nine months old, was sent on Sept. 9th, 1890, to the Halifax Infirmary by Dr. Windle of Ovenden. The mother said the child had been playing with a nutshell in its mouth, and whilst doing so had suddenly commenced coughing and the nutshell had disappeared. She had been unable to find the nutshell, and as the child continued coughing and began to breathe in a peculiar manner she had taken it to Dr. Windle, who immediately sent her to the Halifax Infirmary.

On admission the child's respiration was stridulous, the stridor was heard whilst standing near the child and without any auscultation. My colleague, Dr. S. C. Smith, saw the ehild with me and we came to the conclusion that tracheotomy ought to be done at once. The child was placed under the influence of chloroform and I immediately performed tracheotomy. The low operation was done and a bivalve tracheotomy tube was used. The child was placed in a cot and directions were given to the nurse that any vomit or expectoration was to be kept and carefully examined to see if the piece of nut shell came away. Four days later, no nutshell having been found, the tube was removed and the finger placed over the tracheal opening, but dyspncea immediately occurred and I was obliged to replace the tube when respiration became normal. On Sept. 16th the child was again ehloroformed and an attempt was made to find the nutshell by a probe passed into the larynx from the tracheal wound, but in vain. No nutshell having been discovered either in the expectoration or in the vomit, and the child being still unable to breathe through the natural passage, I was Eriven to the conclusion that the piece of shell was in the larynx and that thyrotomy ought to be performed. On Sept. 20th the thyroid cartilage was exposed by a median incision and divided with a scalpel. On holding the two halves apart no nutshell was seen and the interior of the larynx was perfectly normal. A curved, blunt-pointed director was then passed down the trachea from the larynx but it was arrested at the lower end of the proximal portion of the trachea. The trachea was then slit from above down-

1 The LaNCer, Jan. 10th, 1801. wards where it was found that the obstruction was due to cicatricial contraction of the portion of the trachea in contact with the upper part of the tracheotomy tube. No foreign body was to be seen. The tube was replaced at a higher point in the trachea-i.e., nearer the larynx in order to prevent recontraction of the stenosed part-and the wound was sewn up, no stitches being placed in the thyroid cartilage as the two halves came well together. The patient went on very well and four days later, the child being able to breathe through the natural passage, the tube was removed. The wound gradually closed and the child was discharged from the hospital on Oct. 16th, perfectly well and able to say "mamma," the only word it had been able to utter previously to the operation. I learnt afterwards from Dr. Windle that the child died some weeks later quite suddenly, probably from subsequent stenosis accompanied with some spasm of the larynx or trachea.

King Cross, Halifax.

RADICAL CURE OF HERNIA, THE RESULT OF INFLAMMATION SUBSEQUENTLY TO HERNIOTOMY.

BY SURGEON-MAJOR D. CHARLES DAVIDSON, I.M.S., CIVIL SURGEON, SATARA, INDIA.

IN performing the operation of herniotomy the primary object of the surgeon, it is needless to say, is to remove the obstruction causing the strangulation, but there is a secondary object-riz, to effect as far as practicable such a cure as will prevent the descent of the gut that had indirectly led to the strangulation which had necessitated the operation. In exceptional instances the means usually employed for this purpose cannot be resorted to, and this occurred in the case mentioned below. Occasionally, under such circumstances, nature brings about what the surgeon for sufficient reasons had not attempted to perform. In the undermentioned case the patient was in such an exhausted condition that it was necessary to get him off the operating-table as quickly as possible after dividing the stricture and reducing the hernia.

A Mahomedan aged about thirty-eight, by trade a shopkeeper, was admitted into the Civil Hospital, Satara, on March 2nd, 1893, suffering from strangulated inguinal hernia He stated that he had been ruptured for a considerable time and that on two occasions there had been difficulty in reducing the hernia. He was put under chloroform and reduction by taxis was tried, but without avail. Herniotomy was therefore performed in the usual manner, the sao being opened, and the bowel, which was of a port-wine colour, returned into the abdominal cavity without any difficulty. He was in a very exhausted condition, and it was considered unadvisable to prolong the operation beyond the time that was absolutely necessary. The incision was closed by means of catgut sutures and a dressing of iodoform and cotton-wool was applied. There was no vomiting after the operation, but the patient had four stools slightly tinged with blood. He passed a good night. On the following morning the temperature was $998^{\circ}$, which went up to $101 \cdot 6^{\circ}$ in the evening. The bowels were moved four times, the stools being tinged with blood. A dose of laudanum checked the diarrhoa. On the 5th the temperature went up to $103^{\circ}$. On the 7th the scrotum was found to be enormously swollen and cedematous, with much thickening of the structures round the cord. The temperature was $103^{\circ}$ and there was some discharge of pus from the wound. At first sight the swelling of the scrotum appeared as if caused by a return of the hernia, but such was not the case, it being due to inflammation of the testicle and scrotum. Cold applications were applied. On the 8th the temperature in the evening was $103.2^{\circ}$. The bowels had not been moved since the $3 \mathrm{rd}$.

March 9th: The bowels were not moved; there was no vomiting ; temperature $101^{\circ} .-11 \mathrm{th}$ : The bowels were moved for the first time since the 3rd; the morning temperature was normal, the evening temperature $100^{\circ},-15$ th: The swelling of the scrotum has much subsided. -18 th: The patient is free from fever ; the swelling is subsiding. Up to 